\title{
Comprometimento Organizacional de Servidores Públicos da Geração Y do Rio de Janeiro
}

\section{Organizational Commitment of Public Servants of Generation Y in Rio de Janeiro}

Andréa Pereira Lyrio Barreto

Mestre em Administração e Desenvolvimento Empresarial pelo MADE/UNESA Servidora da Fundação Casa de Rui Barbosa - FCRB, Gabinete da Coordenação Geral de Administração. E-mail: cgpa@rb.gv.br

Isabel de Sá Affonso da Costa Doutora em Administração pela EBAPE/FGV Pesquisadora de Pós-Doutorado na COPPEAD (Universidade Federal do Rio de Janeiro) Professora da Escola de Negócios e Seguros (ENS), Rio de Janeiro

E-mail: isabelsaacosta@hotmail.com

Marco Aurélio Carino Bouzada

Doutor em Administração/COPPEAD (Universidade Federal do Rio de Janeiro)

Professor da Universidade Unigranrio

E-mail: marco.bouzada@gmail.com

Endereço: Andréa Pereira Lyrio Barreto Endereço Rua São Clemente, 134 - Botafogo, Rio de Janeiro - RJ, CEP 22260-002, Brasil.

Endereço: Isabel de Sá Affonso da Costa Rua Senador Dantas, térreo - Centro, Rio de Janeiro - RJ, CEP 20031-205, Brasil.

Endereço: Marco Aurélio Carino Bouzada

Rua Professor José de Souza Herdy, 1160 - Jardim Vinte e Cinco de Agosto, Duque de Caxias - RJ, Brasil, CEP 25071-202, Brasil.
Editor-Chefe: Dr. Tonny Kerley de Alencar Rodrigues

Artigo recebido em 24/11/2021. Última versão recebida em 07/12/2021. Aprovado em 08/12/2021.

Avaliado pelo sistema Triple Review: a) Desk Review pelo Editor-Chefe; e b) Double Blind Review (avaliação cega por dois avaliadores da área).

Revisão: Gramatical, Normativa e de Formatação 


\title{
RESUMO
}

Este artigo apresenta os resultados de uma pesquisa cujo objetivo final consistiu em identificar o componente do comprometimento organizacional predominante entre os servidores pertencentes à geração Y de instituições públicas federais do Poder Executivo localizadas na cidade do Rio de Janeiro. Na revisão de literatura foram abordados os seguintes tópicos: comprometimento organizacional: histórico e conceito; geração y; comprometimento organizacional nas organizações públicas no Brasil; e o modelo utilizado nesta pesquisa (modelo de Três Componentes do Comprometimento Organizacional de Meyer e Allen afetivo, instrumental e normativo). A abordagem metodológica foi quantitativa. Quanto aos fins, a pesquisa foi descritiva e, quanto aos meios, foi adotado o método survey. Os resultados demonstraram que o componente predominante é o afetivo, indicando que os servidores da geração Y detêm uma grande ligação emocional, sentimento de lealdade e identificação com a organização onde trabalham. O componente instrumental ficou em segundo lugar e o normativo em terceiro. Os resultados obtidos podem subsidiar os gestores públicos a criarem estratégias e políticas de desenvolvimento de recursos humanos alinhadas às características e expectativas desses servidores da geração $\mathrm{Y}$, de modo a fomentar o comprometimento com os objetivos e metas organizacionais.

Palavras-chave: Comprometimento Organizacional. Geração Y. Servidores Públicos Federais. Gestão de Pessoas.

\begin{abstract}
This article presents the results of a research that aimed at identifying which organizational commitment component predominates among public service employees of generation $\mathrm{Y}$ in Brazilian federal public organizations located in Rio de Janeiro city. Some topics were discussed within literature review: organizational commitment; generation Y; organizational commitment in Brazilian public organizations; and the model used in this research (The Three Components of Organizational Commitment model of Meyer and Allen - affective, instrumental and normative). The methodological approach was a descriptive quantitative survey. The results showed that the predominant component was the affective one, suggesting the generation $\mathrm{Y}$ servants have a strong emotional connection, a sense of loyalty and identification with the organizations they work for. The instrumental component was ranked as the second and the normative as the third. The results can support public managers to create human resource development strategies and policies consistent with the characteristics and expectations of the generation $\mathrm{Y}$ employees in order foster commitment with organizational goals and objectives.
\end{abstract}

Keywords: Organizational Commitment. Generation Y. Public Servants. People Management. 


\section{INTRODUÇÃO}

O fator humano desempenha, reconhecidamente, um papel fundamental no crescimento e desenvolvimento das organizações. Logo, buscar conhecer melhor os empregados para desenvolver processos de gestão de recursos humanos mais adequados, buscando maior qualidade e melhores resultados para a organização torna-se um grande desafio, para organizações públicas e privadas.

A relação indivíduo-organização é complexa, como pode ser percebido pela multiplicidade de construtos estudados no âmbito do comportamento organizacional (ROBBINS, 2006). Esses construtos buscam dar conta de como os indivíduos e grupos processam psicologicamente os eventos que ocorrem dentro do ambiente de trabalho, buscando compreender, entre outros aspectos, o que vincula um indivíduo ao seu trabalho e o que o torna motivado e interessado - vínculo este complexo e multidimensional. Conhecer o que leva os indivíduos a se identificarem com a organização e seus objetivos, desejando manter-se parte dela é fundamental para que a organização desenvolva um ambiente estável, prazeroso, favorecendo a produtividade e os bons resultados do trabalho.

O comprometimento organizacional pode ser entendido como o conjunto das percepções e atitudes que levam os indivíduos a se comprometerem com os objetivos e metas da organização onde trabalham, podendo surgir em três dimensões: afetiva (envolvimento emocional, lealdade com a organização), instrumental (custos associados com a saída do indivíduo da organização) e normativa (sentimento de obrigação e responsabilidade para com a organização) (MEYER; ALLEN, 1991).

Diversas pesquisas sobre o comprometimento organizacional vêm sendo realizadas ao longo dos anos, tendo como foco de análise organizações públicas e privadas - refletindo o interesse no entendimento dos mecanismos que levam os funcionários a se sentirem comprometidos de maneira a contribuir com um melhor desempenho da organização (LIZOTE; VERDINELLI; NASCIMENTO, 2017).

Pesquisas como as de Pires e Macedo (2006), Rowe e Bastos (2007) indicam que o comprometimento de servidores públicos apresenta bases diferentes do comprometimento de empregados do setor privado. Segundo esses autores, as razões pelas quais os indivíduos se comprometem com as organizações públicas no Brasil variam desde a busca pela estabilidade no emprego, melhores salários ou até a identificação e o valor que atribuem à sua missão e objetivos para a sociedade. Também Oliveira, Costa, Bouzada e Salles (2018) encontraram 
diferenças nas dimensões predominantes entre servidores públicos e terceirizados atuando como contratados no setor público.

Cabe destacar que o comprometimento organizacional é, como todo construto atitudinal, baseado em valores (ROBBINS, 2006). Logo, cabe supor - com o suporte dos achados de Silva et al (2015) - que o que poderia ser fator de comprometimento nas gerações anteriores, pode não ser mais um fator relevante para as novas gerações. Desta forma, entender o que é mais relevante em cada geração contribui para a compreensão dos mecanismos de motivação e para o consequente aumento do comprometimento com a organização num contexto de frequentes mudanças (LIPKIN; PERRYMORE, 2010).

O interesse no tema da presente pesquisa teve sua origem na busca do entendimento do comportamento dos indivíduos da geração Y submetidos às normas, legislações e estrutura das organizações públicas federais, assim como da identificação de mecanismos que levam esses indivíduos a se comprometerem com a missão e o trabalho nessas organizações.

Logo, conhecer os componentes do comprometimento organizacional dessa nova geração de servidores, que vão, ao longo do tempo, constituir a maior parte do quadro de funcionários, é essencial para que os gestores públicos criem estratégias e políticas de recursos humanos adequadas a essa nova realidade.

Frente ao exposto, este estudo tem como objetivo principal identificar o componente do comprometimento organizacional, segundo o modelo de Meyer e Allen (1991), predominante nos servidores pertencentes à geração $\mathrm{Y}$ em instituições públicas federais do Poder Executivo. Também foi estabelecido, como objetivo secundário, identificar e analisar a existência de padrões de comprometimento em cada Instituição da amostra.

O escopo da presente pesquisa foi delimitado às instituições públicas federais do Poder Executivo sediadas na cidade do Rio de Janeiro. A pesquisa ocorreu nos meses de novembro e dezembro de 2017 e janeiro de 2018.

O estudo do comprometimento organizacional em instituições públicas, que visam ao bem comum da sociedade e são geridas por recursos públicos, justifica-se por questões acadêmicas e práticas. Uma vez que o Estado tem a obrigação de prestar serviços à população com eficiência e excelência, o estudo do comprometimento dos servidores passa a ter papel fundamental para dar base ao desenvolvimento de políticas de gestão de pessoas que viabilizem a realização dessa missão. Identificar o que leva seus servidores a um maior comprometimento com os objetivos organizacionais pode levar ao Estado melhores índices de desempenho, produtividade e engajamento, diminuir o absenteísmo, a rotatividade e a 
elaborar melhores estratégias (BORGES-ANDRADE; CAMESCHI; XAVIER, 1990; OLIVEIRA; COSTA; BOUZADA; SALLES, 2018).

\section{REFERENCIAL TEÓRICO}

\subsection{Comprometimento organizacional: histórico e conceito}

Bastos (1994) explica que, quando utilizado na linguagem do cotidiano, o termo ‘comprometimento' está associado a múltiplos significados. Na linguagem acadêmica, o conceito está associado a um sentido positivo e se refere à noção de envolvimento, engajamento, ajustamento; refere-se a uma propensão a agir, a se comportar de determinada forma.

No campo do comportamento organizacional, o comprometimento é um "enlace psicológico, desenvolvido pelo indivíduo, no trabalho, a partir de suas percepções e relações com os elementos ambientais" (GAMA, 1997, p. 29). O construto do comportamento organizacional começou a ser pesquisado em meados do século XX por Mowday, Porter e Steers (1979). No Brasil, os primeiros trabalhos sobre este tema foram realizados por BorgesAndrade, Cameshi e Xavier (1990) e Bastos (1994).

$\mathrm{Na}$ busca da compreensão da relação indivíduo-organização, o construto do comprometimento organizacional visa compreender o que vincula um indivíduo ao seu trabalho e o que o torna motivado e interessado (TAMAYO; PORTO, 2005). De acordo com Meyer e Allen (1997), observa-se que a maioria dos estudos sobre comprometimento desenvolveu-se na vertente organizacional, onde as pesquisas buscaram entender os fenômenos apresentados nessa relação indivíduo-organização para alcançar novos e melhores resultados para os problemas vivenciados nas empresas.

Observa-se até hoje que não existe uma concordância plena na literatura sobre o significado do termo comprometimento. De acordo com Meyer e Allen (1997), não existe uma definição de comprometimento que seja mais correta do que a outra. Com essa mesma ideia, Mowday, Porter e Steers (1982, p. 21) listam diversas definições oriundas de pesquisas sobre comprometimento organizacional, concluindo que: "dessas definições, fica claro que não existe um verdadeiro consenso com relação à definição correta do construto".

Como resultado desse esforço de levantamento conceitual que, reiteradamente, evidenciava o não-consenso em torno do construto, alguns autores, a partir da década de 1990, reconheceram uma característica importante, que era o seu caráter multidimensional, tal como 
Medeiros et al. (2003, p. 189) afirmam: “[...] tentando entender os indivíduos e seu vínculo com a organização de maneira mais complexa. É consenso hoje, na literatura, que o comprometimento possui múltiplos focos, como organização e carreira, e bases, como afetiva, normativa e instrumental". Referindo-se à abordagem multidimensional do comprometimento, Meyer e Allen (1991, p. 63-64) afirmam que todas as características e definições do construto refletem, pelo menos, três elementos gerais, a saber: "adesão afetiva à organização"; "custos associados percebidos de deixar a organização" e "obrigação de continuar na organização".

No entanto, segundo Medeiros et al. (2003), nas duas últimas décadas, dessas cinco perspectivas conceituais, foram predominantes no estudo sobre comprometimento organizacional as três primeiras (afetiva/atitudinal, instrumental/calculativa, normativa), o que corrobora os enfoques conceituais mencionados por Meyer e Allen (1993).

\subsubsection{Comprometimento afetivo ou atitudinal}

Os estudos referentes ao comprometimento afetivo ou atitudinal têm suas raízes nos trabalhos desenvolvidos por Etzioni (1975) e, posteriormente, nos trabalhos de Mowday, Porter e Steers (1982), que abordam a natureza atitudinal/afetiva desse vínculo do indivíduo com a organização. Esses autores assumem o componente afetivo do comprometimento numa perspectiva atitudinal e afirmam que o comprometimento organizacional pode ser caracterizado de três formas: “(a) uma forte crença e a aceitação dos objetivos e valores da organização; (b) estar disposto a exercer um esforço considerável em benefício da organização, e (c) um forte desejo de se manter membro da organização" (MOWDAY; PORTER; STEERS, 1982, p. 27).

Na década de 90, o componente afetivo também ganhou espaço no modelo teórico multidimensional e na escala de mensuração de Allen e Meyer (1991). Os dois autores entendem que o comprometimento organizacional afetivo é desencadeado por experiências anteriores, principalmente aquelas que satisfizeram necessidades psicológicas do empregado, conduzindo a um envolvimento emocional/psicológico com a organização.

Meyer, Allen e Smith (1993) entendem o comprometimento afetivo como sendo um envolvimento que, para ocorrer, é necessário que haja identificação com os objetivos e os valores organizacionais, representando algo além da simples lealdade passiva, envolvendo uma relação ativa, na qual o indivíduo deseja dar algo de si para contribuir com o bem-estar da organização. (ARAÚJO, 2010). 


\subsubsection{Comprometimento instrumental ou calculativo}

O enfoque instrumental originou-se dos estudos de Becker (1960). Esse autor descreve comprometimento instrumental como uma tendência do indivíduo em se engajar em "linhas consistentes de atividade" e por ele denominado de "side bets" ("aposta lateral"). Segundo Bastos (1994), esse tipo de comprometimento também assume outras denominações, tais como, calculativo ou continuação. Para este autor, o indivíduo permanece na empresa devido aos custos e benefícios associados à sua saída, que seriam a aposta lateral, e assim passa a se engajar em linhas consistentes de atividade para se manter no emprego.

Uma outra abordagem deste enfoque é a escassez de alternativas. Para os empregados que estão comprometidos, na abordagem instrumental ou de continuação, permanecem na organização em função da ausência de oportunidades de uma nova colocação no mercado de trabalho, o indivíduo se sente prisioneiro pelos custos associados ao abandono do trabalho e pelo que a remuneração representa para o sustento de sua vida. Os indivíduos permanecem na organização porque precisam e por falta de alternativas no mercado de trabalho. (MEYER; ALLEN, 1997).

\subsubsection{Comprometimento normativo}

O enfoque normativo do comprometimento organizacional tem suas origens na interseção entre a Teoria Organizacional de Etzioni (1975) e a Psicologia Social de Ajzen e Fishbein (1980) e é considerado uma das principais dimensões do comprometimento organizacional. Este é o último enfoque unidimensional, que se refere ao conjunto de pressões normativas internalizadas pelo indivíduo para que se comporte em consonância com os objetivos e interesses da organização (ALLEN; MEYER, 1990).

\subsection{O Modelo Adotado: Modelo Tridimensional de Meyer e Allen}

O modelo de Meyer e Allen (1991) é um dos mais aceitos na área. O modelo propõe que as dimensões do comprometimento organizacional se apresentam de três formas:

1) Affective commitment, ou comprometimento afetivo: reflete um apego, um envolvimento, identificação com a organização. Segundo Allen e Meyer (1990, p.3), a dimensão afetiva exprime que "Empregados com um forte comprometimento afetivo permanecem na organização porque eles querem (...)"; 
2) Continuance commitment ou comprometimento instrumental: é o comprometimento percebido como custos associados a deixar a organização. Para Allen e Meyer (1990, p.3), "Empregados com (...) comprometimento instrumental permanecem porque eles precisam (...)";

3) Normative commitment ou comprometimento normativo: é percebido como uma obrigação em permanecer na organização, os autores denominaram de obligation e posteriormente fizeram uma reconceitualização para normativo (MEYER et al., 1993). De acordo com Allen e Meyer (1990, p.3), "Empregados com (...) comprometimento normativo permanecem porque eles sentem que são obrigados (...)".

As escalas desenvolvidas por Meyer e Allen se apresentam de dois tipos: uma escala com 24 itens e outra reduzida a 18 itens (MEYER et al., 1993). As escalas são compostas por questões fechadas sobre comprometimento organizacional e são aplicadas no formato Likert. Um terço dos indicadores do instrumento é de comprometimento afetivo, e os demais são de comprometimento instrumental e de comprometimento normativo. No Brasil, esse instrumento tridimensional do comprometimento organizacional foi validado por Medeiros e Enders (1998) e Bandeira, Marques e Veiga (2000).

Nas organizações públicas brasileiras, os estudos que utilizaram o modelo de Meyer e Allen (1991) revelam a predominância do componente afetivo no vínculo organizacional para os servidores efetivos. O componente normativo apresentou baixo relacionamento com o vínculo organizacional e apenas os terceirizados apresentaram o componente instrumental (MORAES; MARQUES, 1997; BANDEIRA et al., 2000; LEITE, 2004; ROWE; BASTOS, 2007; CARVALHO; PAIVA, 2015; OLIVEIRA; COSTA, 2015; DUTRA et al., 2017; OLIVEIRA et al., 2018).

\subsection{Geração Y}

Os indivíduos pertencentes à geração Y, com algumas divergências de períodos, são aqueles nascidos a partir de 1980 até o ano de 1992 (CRAMPTON; HODGE, 2009).

Esses indivíduos que nasceram no início do período classificado como Geração $\mathrm{Y}$ experimentaram um Brasil atravessando uma grande instabilidade econômica na década de 1980 e início dos anos 90, e depois, um pouco mais tarde, o restabelecimento e consolidação da economia e da democracia. A abertura econômica e o controle da inflação prepararam o cenário para uma nova fase no desenvolvimento brasileiro (SILVA et al., 2015). 
Observa-se também na literatura outras denominações para geração Y, assim como: geração do Milênio, geração Digital, geração Net (DUBLIN, 2008; CRAMPTON; HODGE, 2009; TOLBIZE, 2008).

Atualmente, a existência de diferentes gerações atuantes no mercado de trabalho tem sido estudada com o objetivo de levantar as peculiaridades de cada uma delas no que diz respeito às suas crenças, valores e prioridades e de relacionar de que maneira essas características particulares de comportamento de cada uma dessas gerações podem influenciar no comprometimento organizacional (BATISTA, 2010; TOLBIZE, 2008). Logo, conhecer as características desta geração torna-se importante para os gestores das organizações.

Dentre as características apresentadas pela geração Y e que são fundamentais para as organizações, pode-se citar: familiaridade com a tecnologia; alto nível de qualificação; adaptabilidade a mudanças; motivação por desafios; foco nos resultados; valorização do trabalho flexível; voltada a ações sociais; construção e utilização de redes de relacionamento; busca do desenvolvimento contínuo; postura individualizada; necessitam de feedback; postura questionadora; busca do equilíbrio da vida pessoal e profissional; e busca da satisfação (BROADBRIDGE; MAXWELL; OGDEN, 2007; HURST; GOOD, 2009).

Considera-se um dos grandes desafios das organizações na atualidade atrair, manter e reter esses profissionais mais jovens. Devido às suas características, é natural que essa geração não compartilhe da visão de autoridade da geração anterior, cujos valores como obediência e troca de sacrifícios na vida pessoal por estabilidade no emprego eram praticados. A geração Y se sente menos identificada com a empresa, mais independente e se move com mais rapidez, mudando de emprego conforme sua necessidade (SARSUR; PEDROSA; SANT'ANNA, 2003).

A entrada da geração Y no ambiente organizacional parece estar introduzindo novos desafios à gestão de pessoas, uma vez que, ao ingressarem nas organizações, esses jovens encontram, muitas vezes, ambientes de trabalho muitos distintos de suas expectativas (TULGAN, 2009; LIPKIN; PERRYMORE, 2010; CAVAZOTTE; LEMOS; VIANA, 2012).

\subsection{Comprometimento Organizacional nas Organizações Públicas no Brasil}

Os estudos sobre comprometimento organizacional começaram a ser desenvolvidos no Brasil a partir dos anos 90 e até então poucos eram os estudos realizados, sendo que a maioria do referencial sobre o tema era absorvido da literatura estrangeira, principalmente da norte-americana. No entanto, a partir dessa época, as pesquisas sobre o 
tema têm evoluído bastante e diversos são os estudos que abordam a característica multidimensional deste construto, sendo consenso na literatura a existência dos seus múltiplos focos e bases (MEDEIROS et al., 2003).

No Brasil, foram realizadas algumas pesquisas sobre comprometimento organizacional no setor público brasileiro, tais como Borges-Andrade, Cameschi e Xavier (1990); Bastos, Brandão e Pinho (1997); Bastos e Borges-Andrade (1995, 1999); Moraes e Marques (1997); Bandeira, Marques e Veiga (2000); Leite (2004); Rowe e Bastos (2007); Abranches (2011); Carvalho e Paiva (2015); Durão e Silva Filho (2015); Dutra, Oleto, Paiva e Rios (2017); Fernandes, Costa, Lins Filho e Anez (2017); Lizote et al. (2017); e Oliveira et al. (2018).

O comprometimento organizacional nas organizações públicas é influenciado pelo que acontece na sociedade e nas mudanças da gestão pública. As organizações tendem a se modificar rapidamente, na tentativa de se adaptar às mudanças tecnológicas, sociais e econômicas, presenciadas no mundo atual. A sociedade civil e o Estado são as duas instituições políticas mais importantes que assumem novos papéis e formas, produzindo uma nova governança democrática (BRESSER-PEREIRA, 2009).

No Brasil, as mudanças na forma de atuação do setor público se dão a partir da década de 90 com a criação do Plano Diretor de Reforma do Estado, que consistia num novo modelo de desenvolvimento econômico e social, que poderia trazer à sociedade brasileira a perspectiva de um futuro melhor no campo da prestação de serviços sociais e infraestrutura (BRASIL, 1995). O Plano Diretor da Reforma do Aparelho de Estado - PDRAE, de 1995 tinha como proposta explícita dar início à chamada "administração gerencial" (COSTA, 2008). O PDRAE foi criado principalmente para estabelecer diretrizes para a reforma da administração pública brasileira, a fỉm de transformar a cultura burocrática e patrimonialista das instituições públicas num modelo mais eficiente.

Neste sentido, observa-se a necessidade e a importância do comprometimento do indivíduo para com a organização, uma vez que estes novos sistemas gerenciais demandam empregados comprometidos que se identifiquem com os objetivos organizacionais e que atuem nas empresas como sendo seu próprio negócio. Portanto, como tais ideias se mostram plenamente aderentes à realidade do mundo atual, torna-se necessário conhecer mais profundamente sobre o serviço e o servidor público. Sendo assim, é fundamental conhecer o perfil e os determinantes do comprometimento dessa força de trabalho, da qual dependem as organizações públicas, de maneira a melhorar as condições de trabalho, obter maior comprometimento e melhor qualidade nos processos. 
Essas transformações no papel da área de recursos humanos começaram a partir do momento em que a administração pública constatou a necessidade de alterar, profundamente, o perfil da força de trabalho, em direção a um quadro mais qualificado de servidores. Mas, em muitas administrações públicas observa-se certa dificuldade na adoção de novas técnicas de gestão de recursos humanos, resultando em defasagem em relação à evolução do mercado e às mudanças na gestão de RH. Segundo Marconi (2003), há necessidade de desenvolvimento da área de recursos humanos no setor público, de modo a criar condições para a solução de alguns problemas ainda presentes, como a desmotivação dos funcionários e a precariedade no atendimento aos cidadãos.

\section{METODOLOGIA}

Para o desenvolvimento desta pesquisa, foi adotada uma abordagem quantitativa. Quanto aos fins, a pesquisa é descritiva e, quanto aos meios, foi adotado o método survey.

A população desta pesquisa foi constituída por todos os servidores públicos civis federais do Poder Executivo na cidade do Rio de Janeiro pertencentes à geração Y, que são aqueles nascidos entre janeiro de 1980 até dezembro de 1992.

Já a amostra foi composta pelos 119 servidores da geração Y (que responderem adequadamente ao questionário de pesquisa) das seguintes Instituições da Administração Pública Federal com sede no Rio de Janeiro: Agência Nacional do Cinema (ANCINE), Fundação Biblioteca Nacional (FBN), Fundação Casa de Rui Barbosa (FCRB) e Fundação Nacional de Artes (FUNARTE).

$\mathrm{O}$ instrumento de coleta de dados utilizado foi um questionário com perguntas objetivas, dividido em duas partes: a primeira constava de 4 perguntas com a finalidade de identificar as características demográficas dos servidores, como sexo, data de nascimento, nível de instrução e tempo na instituição; a segunda, composta de 18 questões afirmativas, segundo o modelo de questionário proposto por Meyer e Allen (1991). Foi utilizada a escala do tipo Likert de 5 pontos $(1=$ Discordo Totalmente; $2=$ Discordo; $3=$ Indeciso; $4=$ Concordo; 5 = Concordo Totalmente). O método de levantamento foi de corte transversal e foi utilizada a ferramenta Google Forms para a aplicação do questionário e para o levantamento dos dados. A aplicação do questionário foi realizada entre os meses de novembro de 2017 e janeiro de 2018.

A pesquisa foi divulgada para o quadro de funcionários das Instituições através de suas intranets, informando o objetivo do estudo e solicitando colaboração. O questionário foi 
enviado a todos os servidores através de e-mail institucional pelo setor de Recursos Humanos de cada Instituição. Foi usada a ferramenta Google Forms para a aplicação do questionário e para o levantamento dos dados.

Em função do que foi pesquisado e apresentado nas seções anteriores, foram formuladas as seguintes hipóteses para a pesquisa:

Hipótese 1: $\mathrm{CI}>\mathrm{CA}$ - $\mathrm{O}$ componente instrumental (CI) do comprometimento organizacional nos servidores públicos federais do Poder Executivo da geração Y é maior que o componente afetivo (CA);

Hipótese 2: $\mathrm{CI}>\mathrm{CN}$ - $\mathrm{O}$ componente instrumental (CI) do comprometimento organizacional nos servidores públicos federais do Poder Executivo da geração Y é maior que o componente normativo $(\mathrm{CN})$;

Hipótese 3: $\mathrm{CA}>\mathrm{CN}$ - $\mathrm{O}$ componente afetivo (CA) do comprometimento organizacional nos servidores públicos federais do Poder Executivo da geração Y é maior que o componente normativo $(\mathrm{CN})$.

Para os testes estatísticos e identificação das variáveis relevantes nas regressões, o nível de significância adotado foi de 5\%.

\section{RESUltados E DisCUSSÃo}

Dentro desta seção 4, a primeira subseção testa as hipóteses de pesquisa e ataca o objetivo principal. A segunda subseção procura verificar o impacto das características sociodemográficas na intensidade de cada um dos três componentes do comprometimento organizacional. E a terceira subseção lida com o objetivo secundário da pesquisa.

\subsection{Identificação do comprometimento organizacional predominante}

Primeiramente, para identificar o comprometimento afetivo (CA) de cada servidor, foi calculada a mediana das respostas das seis primeiras perguntas do questionário. Dando continuidade, para identificar o comprometimento instrumental (CI) foi calculada a mediana das respostas dos itens 7 a 12 e, por fim, para identificar o comprometimento normativo (CN) foi calculada a mediana dos itens 13 a 18 do questionário.

A Tabela 1 a seguir demonstra o resultado do cálculo das medianas globais (considerando todos os servidores) da amostra selecionada. 


\section{Tabela 1 - Cálculo das medianas quanto ao tipo de comprometimento}

\begin{tabular}{|c|c|c|c|}
\hline & CA & Cl & CN \\
\hline MEDIANAS & $\mathbf{3 , 5}$ & $\mathbf{2 , 5}$ & $\mathbf{2 , 0}$ \\
\hline
\end{tabular}

Fonte: Elaborado pelos autores.

Para cumprir o objetivo final da pesquisa, que consiste em identificar o componente do comprometimento organizacional, segundo o modelo de Meyer e Allen (1991), predominante nos servidores pertencentes à geração $\mathrm{Y}$ em instituições públicas federais do Poder Executivo, foi utilizado o teste de comparação de medianas (Mann-Whitney) unicaudal para análise de cada uma das três hipóteses formuladas.

Como o valor p obtido na hipótese $1(99,95 \%)$ foi maior que o nível de significância adotado de 5\%, a hipótese nula deste teste não pode ser rejeitada; dessa forma a primeira hipótese de pesquisa $(\mathrm{CI}>\mathrm{CA})$ não pode ser aceita.

No caso da hipótese 2, o valor p obtido $(<0,01 \%)$ foi menor que o nível de significância adotado de 5\%, a hipótese nula deste teste é rejeitada; dessa forma a segunda hipótese de pesquisa $(\mathrm{CI}>\mathrm{CN})$ pode ser aceita. O mesmo ocorreu no caso da terceira hipótese de pesquisa $(\mathrm{CA}>\mathrm{CN})$, que pode ser aceita.

Com o resultado da hipótese 1, em que não há evidências para aceitar a hipótese alternativa (CI > CA), não foi possível concluir, dentre os comprometimentos afetivo e instrumental, qual é o predominante. No entanto, é possível realizar um teste de hipóteses similar ao realizado para verificar a hipótese de pesquisa 1, mas dessa vez tendo como hipótese alternativa $\mathrm{CA}>\mathrm{CI}$. Esse procedimento não visa verificar nenhuma das hipóteses de pesquisa, mas, como já foi constatado que não há evidências estatísticas de que CI>CA, é preciso verificar se há evidências de que $\mathrm{CA}>\mathrm{CI}$, para confirmar se CA é mesmo o componente predominante e assim, atender ao objetivo final da pesquisa.

Com o novo teste de hipótese, o valor p obtido $(0,05 \%)$ foi menor que o nível de significância adotado de 5\%, a hipótese nula deste teste é rejeitada; dessa forma a hipótese $\mathrm{CA}>\mathrm{CI}$ pode ser aceita e assim pode-se confirmar que CA é mesmo o componente predominante, o que nos leva a atender ao objetivo final da pesquisa.

Com o resultado apresentado acima, a primeira hipótese de pesquisa foi refutada, pois concluiu-se que o componente do comprometimento organizacional predominante nos servidores públicos federais do poder Executivo pertencentes à geração Y na cidade do Rio de Janeiro é o componente afetivo. Esses servidores demonstram uma forte ligação emocional e se identificam com os objetivos e valores da organização onde trabalham. Segundo Bastos 
(1994), o comprometimento afetivo é um vínculo manifestado pelos indivíduos por sentimentos como desejar, gostar, manter-se leal, de se esforçar, dedicando-se às metas, objetivos e valores da organização.

Tal resultado corrobora a literatura e outras pesquisas. Moraes e Marques (1997), Leite (2004), e Oliveira et al. (2018), conforme apontado no item 2.4, também verificaram a predominância do componente afetivo nos servidores públicos.

\subsection{Identificação de padrões de comprometimento segundo características sociodemográficas e seu impacto sobre o comprometimento organizacional}

Com o propósito de identificar e analisar a existência de padrões de comprometimento segundo características sociodemográficas dos servidores, foram realizadas três regressões múltiplas, uma para cada componente do comprometimento organizacional afetivo, instrumental e normativo. As variáveis sociodemográficas coletadas na primeira parte do questionário foram as variáveis explicativas e o componente do comprometimento organizacional em questão foi a variável dependente.

Os resultados da primeira regressão (componente afetivo) estão na Tabela 2 a seguir.

Tabela 2. Regressão múltipla - Variáveis sociodemográficas - Componente Afetivo

\begin{tabular}{|c|c|c|c|c|c|c|}
\hline & Coeficientes & Erro padrão & Stat $t$ & valor $-P$ & $95 \%$ inferiores & 95\% superiores \\
\hline Interseção & 3,01 & 1,00 & 3,02 & 0,00 & 1,03 & 4,99 \\
\hline $\operatorname{SEXO}(M=0 ; F=1)$ & 0,25 & 0,17 & 1,43 & 0,15 & 0,10 & 0,59 \\
\hline IDADE & 0,00 & 0,03 & 0,02 & 0,98 & 0,06 & 0,06 \\
\hline TEMPO NA INSTITUIÇÃO: & 0,01 & 0,03 & 0,28 & 0,78 & 0,07 & 0,06 \\
\hline ENSINO SUPERIOR & 0,23 & 0,40 & 0,57 & 0,57 & 0,57 & 1,03 \\
\hline PÓS-GRADUAÇÃO & 0,01 & 0,41 & 0,01 & 0,99 & 0,81 & 0,80 \\
\hline MESTRADO & 0,55 & 0,42 & 1,32 & 0,19 & 0,28 & 1,38 \\
\hline DOUTORADO & 0,37 & 0,60 & 0,63 & 0,53 & 0,81 & 1,56 \\
\hline
\end{tabular}

Fonte: Elaborado pelos autores

O teste acima gerou um R-Quadrado de 0,07. Como pode ser observado, não houve nenhuma variável significativa a 0,05 . O mesmo procedimento foi utilizado para os dois outros componentes (instrumental e normativo) e os resultados foram similares, com valores de R-Quadrado de 0,06 e 0,04, respectivamente.

Como pode ser observado através da análise dos resultados, encontramos um Rquadrado muito baixo para todos os componentes do comprometimento organizacional 
(afetivo, instrumental e normativo); ou seja, as variáveis estudadas (sexo, idade, tempo na instituição e nível de instrução) não são capazes de explicar satisfatoriamente nenhum componente do comprometimento organizacional. Logo, conclui-se que diversas outras variáveis (psicológica, contextuais, por exemplo), não contempladas neste estudo, poderão ser capazes de explicar o comprometimento dos servidores públicos federais da geração Y no Poder Executivo na Cidade do Rio de Janeiro.

Como comentado, não há valor-P relevante para nenhuma das variáveis explicativas. Porém, foi possível constatar que, se for utilizado o nível de significância a 10\%, a variável tempo na instituição iria influenciar positivamente o comprometimento instrumental; ou seja, a cada ano trabalhado, o comprometimento instrumental do servidor público federal tenderia a aumentar. Segundo Meyer e Allen (1997), empregados comprometidos instrumentalmente permanecem na organização porque precisam. Este componente pode ser relacionado com a conformidade, ou seja, as atitudes e comportamentos são adotados com o objetivo de recebimento de recompensas. O indivíduo faz uma relação custo-benefício (privilégios, salário, benefícios, assistências, por exemplo) e faz uma avaliação pela permanência ou saída da organização. (BASTOS, 1994; BASTOS; BRANDÃO; PINHO, 1997).

\subsection{Identificação de padrões de comprometimento em cada instituição da amostra}

Finalmente, para atender ao objetivo secundário proposto, ou seja, identificar e analisar a existência de padrões de comprometimento em cada Instituição da amostra foram aplicados os mesmos procedimentos estatísticos dos casos anteriormente, mas desta vez considerando cada instituição separadamente.

Ao analisar os resultados, constatou-se que os componentes predominantes do comprometimento organizacional nos servidores pertencentes à geração Y da ANCINE (18 respondentes) são o componente afetivo e o componente instrumental (não há diferença estatisticamente significativa entre eles). No caso da FBN (46 respondentes), o componente predominante é o afetivo, seguido do instrumental e do normativo.

Já em relação à FCRB (34 respondentes), o componente afetivo se mostrou predominante. Em segundo lugar, o componente instrumental, e em terceiro, o normativo. Finalmente, os componentes predominantes na FUNARTE (21 respondentes) são o afetivo e o instrumental (não há diferença estatisticamente significativa entre eles). 


\section{CONSIDERAÇÕES FINAIS}

Os resultados da pesquisa permitem concluir que o componente do comprometimento organizacional predominante nos servidores pertencentes à geração $\mathrm{Y}$ das instituições públicas federais do Poder Executivo na cidade do Rio de Janeiro é o componente afetivo - o que demonstra forte ligação emocional, presença de sentimentos de envolvimento e identificação do indivíduo com as metas, valores e objetivos da instituição. Esse resultado refuta a primeira hipótese de pesquisa apresentada, que sugeria que o componente instrumental seria maior que o componente afetivo.

Embora a metodologia utilizada não permita concluir sobre os motivos e razões dos servidores se comprometerem afetivamente com a organização, pode-se especular, a partir da teoria e de achados de pesquisa anteriores, que a predominância do componente afetivo pode ser atribuída ao reconhecimento, por parte dos servidores, da relevância do serviço prestado à sociedade, bem como a algumas práticas e oportunidades eventualmente presentes nas organizações, como participação nas decisões e valorização da capacitação - fatores considerados importantes para elevar o comprometimento afetivo dos servidores.

Já as hipóteses 2 (componente instrumental > componente normativo) e 3 (componente afetivo > componente normativo) de pesquisa foram aceitas, demonstrando que o componente que apresentou o menor índice de relacionamento com o vínculo organizacional dentre os servidores públicos da geração $\mathrm{Y}$ foi o componente normativo, indicando que o sentimento de obrigação para com a organização é a fonte de comprometimento menos significativa.

Verificou-se que o componente instrumental é o segundo mais encontrado nos servidores públicos pertencentes à geração Y.

No que tange à gestão de pessoas, pode-se considerar que esse resultado é interessante do ponto de vista prático, pois os servidores mais comprometidos afetivamente tendem a contribuir para um melhor desempenho individual e organizacional, de forma mais intensa e positiva - o que resulta em melhores resultados para o Estado e, consequentemente, para a sociedade.

Em relação ao impacto das características sociodemográficas na intensidade de cada um dos três componentes do comprometimento organizacional, os resultados revelaram um nível de explicação muito baixo para todos os componentes do comprometimento organizacional: afetivo (7\%), instrumental (6\%) e normativo (4\%); ou seja, levando em conta 
apenas essas variáveis sociodemográficas estudadas, em seu conjunto, elas não são capazes de explicar satisfatoriamente nenhum componente do comprometimento organizacional

Logo, pode-se concluir que fatores de ordem psicológica e contextual, entre outros, não contemplados neste estudo, poderão ser capazes de influenciar e explicar o comprometimento dos servidores públicos federais da geração Y no Poder Executivo.

$\mathrm{Na}$ análise das regressões realizadas, pode ser constatado que nenhuma variável sociodemográfica avaliada apresentou relevância para explicar cada tipo de comprometimento. No entanto, não se pode deixar de mencionar que a variável tempo na instituição mereceria uma investigação mais profunda devido ao fato de apresentar um valor $p$ bem próximo ao nível de significância utilizado (5\%), sugerindo que essa variável poderia influenciar positivamente o comprometimento instrumental; em outras palavras, a cada ano trabalhado, o comprometimento instrumental do servidor público federal tenderia a aumentar.

Em geral, os servidores tendem a permanecer na organização porque precisam; o indivíduo faz realmente uma relação custo-benefício (privilégios, salário, benefícios, assistências, por exemplo) e faz uma avaliação pela permanência ou saída da organização. Em vista disso, o fator tempo na instituição merece uma investigação mais profunda, para que seja mais bem compreendida sua influência no comprometimento instrumental.

Em relação ao objetivo secundário, que consiste em identificar e analisar a existência de padrões de comprometimento em cada Instituição da amostra, identificamos que, com base nos dados apresentados e analisados, os servidores públicos federais pertencentes à geração Y das instituições FBN e FCRB possuem uma tendência ao estilo de comprometimento afetivo, o que demonstra uma grande ligação emocional com a instituição onde trabalham, uma forte identificação com os objetivos e valores da instituição e sentimento de lealdade. Já para as instituições ANCINE e FUNARTE, o componente do comprometimento organizacional predominante são o componente afetivo e o componente instrumental (não há diferença estatisticamente significativa entre eles), indicando que os seus servidores detêm uma grande ligação emocional com a instituição, sentimento de lealdade e identificação com seus objetivos, mas permanecem na instituição em função do custos e benefícios associados à sua saída, que demandaria sacrifícios econômicos, sociais ou psicológicos, e assim permanecem na instituição em função da ausência de oportunidades de uma nova colocação no mercado de trabalho. Um aspecto importante a ser examinado entre as instituições federais seria se a predominância da missão da instituição ter algo de concreto a oferecer à sociedade influenciaria diretamente nas diferenças apresentadas dos componentes do comprometimento. 
De uma maneira geral, o resultado encontrado com predominância do componente afetivo nos servidores públicos federais da geração Y pode ser considerado um resultado interessante, pois põe certos "mitos" em xeque. A literatura da área de gestão aponta que a geração Y apresenta como algumas das principais características: a valorização de uma gestão horizontal sem controles rígidos, a existência de jovens individualistas e o desejo pela flexibilidade de horário. Tais características, por serem opostas ao que geralmente encontramos nas organizações públicas federais, podem ser colocadas em segundo plano quando se depararem com outros fatores considerados importantes, como: a estabilidade; o plano de aposentadoria; a jornada de trabalho reduzida, entre outras. Ainda são poucas as pesquisas qualitativas na área, mas essa abordagem de pesquisa poderá ajudar a entender os fatores que levam essa nova geração a se interessar pelo trabalho no setor público.

Os resultados desta pesquisa devem contribuir para que os gestores da administração pública possam conhecer o componente predominante de comprometimento organizacional da maior força de trabalho dos seus servidores (geração Y), o que os leva a se comprometerem com a instituição onde trabalham, de modo a garantirem bons resultados para o Estado e para a sociedade. Nesse sentido, os resultados obtidos possuem grande relevância para a administração pública, pois demonstram que os gestores públicos deveriam criar estratégias e políticas de desenvolvimento de recursos humanos alinhadas às características e expectativas desses servidores da geração Y, de modo a garantir cada vez mais servidores comprometidos com os objetivos e as metas organizacionais.

Nesse sentido, caberiam esforços no sentido de divulgação da missão, visão e valores da instituição, com a intenção de criar um maior envolvimento dos seus servidores com os problemas e o objetivo da instituição onde trabalham; programas de capacitação e qualificação mais dinâmicos, de modo a criar maior interesse na participação dos servidores; estudos voltados à realocação de servidores em diversas áreas internas com o objetivo de gerar maior motivação, menos rotatividade e melhor desempenho, entre outros.

Como sugestão para futuros trabalhos, recomenda-se o estudo da influência de outras variáveis nos componentes do comprometimento organizacional, como por exemplo: estado civil, cargo, função, entre outras, para melhor compreender o fenômeno, ampliando a compreensão do comprometimento e seus fatores dentro das instituições públicas federais do Poder Executivo; estudos utilizando dados longitudinais, a fim de entender as possíveis mudanças no comportamento dos indivíduos ao longo do tempo; replicar este estudo com uma amostra maior para que haja mais chance de serem encontrados resultados estatisticamente significativos, especialmente no que se refere à influência das variáveis 
sociodemográficas; a realização de outras pesquisas semelhantes em outras organizações públicas, como o Poder Judiciário ou Poder Legislativo; e, por fim, em função das limitações intrínsecas da abordagem quantitativa, cujos resultados são interpretados somente de forma estatística, estudos qualitativos adicionais poderiam trazer melhores interpretações, principalmente quanto à análise das hipóteses rejeitadas.

\section{REFERÊNCIAS}

ABRANCHES, L. F. Satisfação com o trabalho e comprometimento organizacional de novos servidores públicos: um estudo de caso na Receita Federal do Brasil. 2011. $134 \mathrm{f}$. Dissertação (Mestrado em Administração Pública) Escola Brasileira de Administração Pública e de Empresas, Fundação Getúlio Vargas, 2011.

AJZEN, I.; FISHBEIN, M. Understanding attitudes and predicting social behavior. Englewood Cliffs, N.J. Prentice-Hall, 1980.

ALLEN, N. J.; MEYER, J. P. The measurement and antecedents of affective, continuance and normative commitment to the organization. Journal of Occupational Psychology, v.63, p.1$18,1990$.

ARAÚJO, S. M. Comprometimento organizacional à luz do modelo conceitual das três dimensões de Meyer e Allen: um estudo de caso no IFRN - Campus Natal. Dissertação (Mestrado em Administração). Universidade Potiguar, 2010.

BANDEIRA, M. L.; MARQUES, A. L.; VEIGA, R. T. As dimensões múltiplas do comprometimento organizacional: um estudo na ECT/MG. Revista de Administração Contemporânea, v. 4, n. 2, p. 133-157, 2000.

BASTOS, A. V. B. Comprometimento no trabalho: a estrutura dos vínculos do trabalhador com a organização, a carreira e o sindicato. Tese de Doutorado (Psicologia) Instituto de Psicologia, Universidade de Brasília, Brasília, 1994.

BASTOS, A. V. B.; BORGES-ANDRADE, J. E. Comprometimento no trabalho: identificando padrões de comprometimento do trabalhador com a organização, a carreira e o sindicato. Revista Brasileira de Administração Contemporânea, v.1, n. 6. p. 219-240, 1995.

BASTOS, A. V. B.; BRANDÃO, M. G. A.; PINHO, A. P. M. Comprometimento organizacional: uma análise do conceito expresso por servidores universitários no cotidiano de trabalho. Revista de Administração Contemporânea, v.1, n. 2, p. 97-120, 1997.

BATISTA, F. H. A. Grupos geracionais e o comprometimento organizacional: um estudo em uma empresa metalúrgica de Caxias do Sul. 2010, 111 p. Dissertação (Programa de PósGraduação em Administração). Caxias do Sul: Universidade de Caxias do Sul, 2010. 
BECKER, H. S. Notes on the concept of commitment. American Journal of Sociology, v. 66. n. 1, p. 32-40, 1960.

BECKER, T. E. Foci and bases of commitment: are they distinctions worth making? Academy of Management Journal, v.35, n.1, p.232-244, 1992.

BORGES-ANDRADE, J. E.; CAMESCHI, C. E.; XAVIER, O. S. Comprometimento organizacional em instituição de pesquisa: diferenças entre meio e fim. Revista de Administração, v. 25, n. 4, p. 29-43, 1990.

BRASIL. Ministério da Administração Federal e Reforma do Estado. Plano Diretor da Reforma do Aparelho do Estado. Brasília: Imprensa Nacional, 1995.

BRESSER-PEREIRA, L. C. Construindo o estado republicano: democracia e reforma da gestão pública. Rio de Janeiro: Ed. FGV, 2009.

BROADBRIDGE, A. M.; MAXWELL, G. A.; OGDEN, S. M. Experiences, perceptions and expectations of retail employment for Generation Y. Carreer Development International, v.12, n. 6, p. 523-544, 2007.

CARVALHO, J. D.; PAIVA, K. C. M. Comprometimento organizacional no serviço público: um estudo em uma unidade do Instituto Nacional de Seguro Social em Minas Gerais. In: Encontro Nacional da Associação Nacional de Pesquisa e Pós-Graduação em Administração, 39. Belo Horizonte, Anais ... Belo Horizonte, ANPAD, 2015.

CAVAZOTTE, F. S. C. N.; LEMOS, A. H. C.; VIANA, M. D. Novas gerações no mercado de trabalho: expectativas renovadas ou antigos ideais. Cad. EBAPE.BR, v.10, n.1, art. 9, p.162-180, 2012.

COSTA, F. L. 200 anos de administração pública; 200 anos de reformas. Revista de Administração Pública, v. 42, n. 5, p: 829 - 874, 2008.

CRAMPTON, S. M.; HODGE, J. W. Generation Y: unchartered territory. Journal of Business \& Economics Research, v. 7, n. 4, p. 1-6, 2009.

DUBLIN, L. Leadership preferences of a generation Y cohort. Journal of Leadership Studies, v. 2, n. 1, p. 43-59, 2008.

DURÃ̃, A. A. X.; SILVA FILHO, A. I. Gestão de Pessoas na Administração Pública: um estudo sobre a relação entre as políticas e práticas de gestão de pessoas e o comprometimento organizacional em um órgão da administração pública federal direta. In: V Encontro de Gestão de Pessoas e Relações de Trabalho - EnGPR, 2015, Salvador. Anais... Salvador: ANPAD, 2015.

DUTRA, M. R. S.; OlETO, A. F.; PAIVA, K. C. M.; RIOS, J. E. Comprometimento Organizacional: um estudo comparativo entre gerentes e não gerentes do setor público mineiro. In: VII Encontro de Administração Pública e Governança - EnAPG. São Paulo. Anais... São Paulo: ANPAD, 2017. 
ETZIONI, A. Análise comparativa de organizações complexas: sobre o poder, o engajamento e seus correlatos. Rio de Janeiro: Zahar, 1975.

FERNANDES, L. T.; COSTA, L. S.; LINS FILHO, M. L.; ANEZ. M. E. M. Comprometimento Organizacional: Um estudo comparativo entre empresas públicas e privadas. In: VI Encontro de gestão de pessoas e relações de trabalho - EnGPR. Curitiba. Anais... Curitiba: Associação Nacional de Programas de Pós-Graduação em Administração ANPAD, 2017.

GAMA, A. L. G. Percepção do sistema de avaliação de desempenho e o comprometimento organizacional. Dissertação de Mestrado (Psicologia), Universidade de Brasília, Brasília, DF, 1997.

HURST, J.; GOOD, L. Generation Y and career choice: the impact of retail career perceptions, expectation and entitlement perceptions. Career Development International, v. 14, n. 6, 2009.

LEITE, C. F. F. O. Comprometimento organizacional na gestão pública: um estudo de caso em uma universidade estadual. 2004. 215 f. Dissertação de Mestrado (Administração) Escola de Administração, Universidade Federal da Bahia, Salvador, 2004.

LIPKIN, N.; PERRYMORE, A. A geração Y no trabalho: como lidar com a força de trabalho que influenciará definitivamente a cultura da sua empresa. Rio de Janeiro: Elsevier, 2010.

LIZOTE, S. A.; VERDINELLI, M. A.; NASCIMENTO, S. Relação do comprometimento organizacional e da satisfação no trabalho de funcionários públicos municipais. Rev. Adm. $\begin{array}{llllll}\text { Pública, v. } & 51, \mathrm{n} . & 6, \mathrm{p} . & 947-967, & 2017 . & \text { Disp. }\end{array}$ http://www.scielo.br/scielo.php?script=sci_arttext\&pid=S0034-76122017000600947. Acesso em $3 / 12 / 2020$.

MARCONI, N. A evolução do perfil da força de trabalho e das remunerações nos setores público e privado ao longo da década de 1990. Revista do Serviço Público, v. 54, n. 1, p. 9$37,2003$.

MEDEIROS, C. A. F.; ALBUQUERQUE, L. G.; GLENDA, M. S.; MARQUES, M. Comprometimento organizacional: o estado da arte da pesquisa no Brasil. Revista de Administração Contemporânea, v.7, n. 4, p.187-209, 2003.

MEDEIROS, C. A. F.; ENDERS, W. T. Validação do modelo de conceitualização de três componentes do comprometimento organizacional. Revista de Administração Contemporânea, v.2, n.3, p.67-87, 1998.

MEYER, J. P.; ALLEN, N. J. A three-component conceptualization of organization commitment. Human Resource Management Review, v.1, n.1, p. 61-89, 1991.

MEYER, J. P.; ALLEN, N. J. A. Organizational commitment: evidence of career stage effects? Journal of Business Research, v. 26, p. 49-61, 1993. 
MEYER, J. P.; ALLEN, N. J. A. Commitment in the workplace: theory, research and application.Thousand Oaks, CA: Sage, 1997.

MEYER, J. P.; ALLEN, N. J.; SMITH, C. A Commitment to organizations and occupations: extension and test of a three-component conceptualization. Journal of Applied Psychology, v.78, n.4, p. 538-551, 1993.

MORAES, L. F. R.; MARQUES, A. L. Comprometimento organizacional: Um estudo de caso comparativo em universidades federais mineiras. In: Encontro Nacional da Associação Nacional de Pesquisa e Pós-Graduação em Administração, 21, Rio de Janeiro. Anais... Rio de Janeiro: ANPAD, 1997.

MOWDAY, R. T.; PORTER, L. W.; STEERS, R. M. Employee-organization linkages: the psychology of commitment, absenteism and turnover. New York: Academic Press, 1982.

MOWDAY, R. T.; STEERS, R. M.; PORTER, L. W. The measurement of organizational commitment. Journal of Vocational Behavior, v. 14, p. 224-247, 1979.

OlIVEIRA, G. A.; COSTA, I. S. A.; BOUZADA, M. A. C.; SAlleS, D. M. R. Organizational commitment: a study of public and outsourced servers of a Brazilian public university. Reuna, v. 23, n. 2, p. 60-76, 2018. Disp. em http://www.spell.org.br/documentos/ver/51157/comprometimento-organizacional--estudocom-servidores-publicos-e-terceirizados-de-uma-ifes/i/pt-br. Acesso em 4/12/2020.

OLIVEIRA, L. B.; COSTA, E.M.T.C.M. Satisfação no trabalho e comprometimento organizacional de trabalhadores efetivos e terceirizados: um estudo comparativo na Universidade Federal do Estado do Rio de Janeiro (UNIRIO). In: Encontro de Gestão de Pessoas e Relações de Trabalho. Anais... Salvador: ANPAD, 2015.

PIRES, J. C. S.; MACEDO, K. B. Cultura organizacional em organizações públicas no Brasil. Revista de Administração Pública, Rio de Janeiro, v. 40, n.1, p. 81-105, 2006.

ROBBINS, S. Comportamento organizacional. 11. ed. São Paulo: Pearson, 2006.

ROWE, D. E. O.; BASTOS, A. V. B. Organização e/ou carreira? Comparando docentes de IESs públicas e privadas quanto à estrutura de seus vínculos de comprometimento no trabalho. In: Encontro da Associação Nacional de Pesquisa e Pós-Graduação em Administração, 31. Anais... Rio de Janeiro: ANPAD, 2007.

SARSUR, A. M.; PEDROSA, R. R.; SANT'ANNA, A. S. Onde estão os talentos? Onde está a gestão de recursos humanos? In: Encontro da Associação Nacional de Pesquisa e PósGraduação em Administração, 27, Atibaia. Anais... Atibaia: ANPAD, 2003.

SILVA, R. C.; DUTRA J. S.; VELOSO, E. F. R.; FISCHER, A. L.; TREVISAN, L. N. Generational perceptions and their influences on organizational commitment, Management Research: The Journal of the Ibero american Academy of Management, v. 13, n.1, p. 530, 2015.

TAMAYO, A.; PORTO J. B. (Org.). Valores e comportamento nas organizações. Petrópolis: Vozes, 2005. 
TOLBIZE, A. Generational differences in the workplace. Research and Training Center on Community Living, University of Minnesota, Minneapolis, 2008.

TULGAN, B. Not everyone gets a trophy: how to manage generation Y. San Francisco: John Wiley, 2009.

\section{Como Referenciar este Artigo, conforme ABNT:}

BARRETO, A. P. L; COSTA, I. S. A; BOUZADA, M. A. C. Comprometimento Organizacional de Servidores Públicos da Geração Y do Rio de Janeiro. Rev. FSA, Teresina, v.18, n. 12, art. 1, p. 3-25, dez. 2021.

\begin{tabular}{|l|c|c|c|}
\hline \multicolumn{1}{|c|}{ Contribuição dos Autores } & $\begin{array}{c}\text { A. P. L. } \\
\text { Barreto }\end{array}$ & $\begin{array}{c}\text { I. S. A. } \\
\text { Costa }\end{array}$ & $\begin{array}{c}\text { M. A. C. } \\
\text { Bouzada }\end{array}$ \\
\hline 1) concepção e planejamento. & $\mathrm{X}$ & $\mathrm{X}$ & \\
\hline 2) análise e interpretação dos dados. & $\mathrm{X}$ & & $\mathrm{X}$ \\
\hline 3) elaboração do rascunho ou na revisão crítica do conteúdo. & $\mathrm{X}$ & $\mathrm{X}$ & $\mathrm{X}$ \\
\hline 4) participação na aprovação da versão final do manuscrito. & $\mathrm{X}$ & $\mathrm{X}$ & $\mathrm{X}$ \\
\hline
\end{tabular}

